\title{
Medicinally Important Compounds in the Flowers of Three Higher Plants: Cannabis, Saffron, and Epiphyllum oxypetalum
}

\author{
Aayushi Patel ${ }^{1,2}$, Shrina Patel ${ }^{1,2}$, Pravallika Sanke ${ }^{2}$, Shobha Potlakayala ${ }^{2}$ and Sairam Rudrabhat- \\ $1 a^{2 *}$
}

${ }^{1}$ Equal Contribution, USA

${ }^{2}$ Penn State Harrisburg, Middletown, PA, USA

*Corresponding author: Sairam Rudrabhatla, Associate Professor of Biology, Program Chair of Biology \& Science, Director for

Central Pennsylvania Research and Teaching Laboratory for Biofuels, Penn State Harrisburg, Middletown, PA, USA

\section{ARTICLE INFO}

Received: 嵊 June 21, 2021

Published: 幽 July 06, 2021

Citation: Aayushi Patel, Shrina Patel, Pravallika Sanke, Shobha Potlakayala, Sairam Rudrabhatla. Medicinally Important Compounds in the Flowers of Three Higher Plants: Cannabis, Saffron, and Epiphyllum oxypetalum. Biomed J Sci \& Tech Res 36(5)-2021. BJSTR. MS.ID.005929.
ABSTACT

Ayurveda and herbal medicine have been around since the early days of medicine and have now been gaining recognition and popularity in modern medicine as secondary metabolites from plants have been identified to possess therapeutic value. Different parts of a plant can be used in herbal medicine, however, flowers, especially female flowers are the most concentrated regions for sites of production of beneficial secondary metabolites in cannabis, saffron and Epiphyllum oxypetalum. Research is slowly focusing on investigating the therapeutic activity of many medicinal plants as well as identifying its secondary metabolites and their role in the pharmacologic activity. Plants such as cannabis, saffron, and Epiphyllum oxypetalum are of growing interest as people are considering nutritionally important diets.

Keywords: Ayurveda; Herbal Medicine; Medicinal Plants; Cannabis; Saffron; Epiphyllum Oxypetalum; Secondary Metabolites

Abbreviations: THC: Tetrahydrocannabinol; CBD: Cannabidiol; CBG: Cannabigerol; CBN: Cannabinol; CBC: Cannabichromene; GC-MS: Gas Chromatography-Mass Spectrometry

\section{Herbal Medicine and Ayurveda}

Ayurveda, also known as traditional Indian medicine, has gained popularity throughout the years. Ayurveda dates back to about 3000 B.C., and the foundation of Ayurveda involves a holistic view of treatment based on different aspects of human life - the body, mind, soul [1]. Although conventional medicine dominates the market, there are many limitations. Many of the medications often have side effects and can cause dependence making them problematic after the medication is discontinued [2]. In such situations, Ayurveda can offer an alternative. The response towards Ayurvedic treatments is generally well as patients experience a reduction or potentially the cessation of their symptoms [2]. Herbal medicine, which stems from Ayurveda, has gained popularity and has been around for numerous years. In the United States, approximately 1 in 5 adults have reported taking an herbal product [3]. In many places, they offer an alternative to pharmaceutical drugs that is more readily available and affordable [4]. Herbal medicine involves the use of different parts of a plant for medicinal and therapeutic value. The parts of the plant include the roots, seeds, berries, leaves, bark, or flowers [5]. Among the many advantages of herbal medicines, another advantage is that they are a renewable source [6].

Herbal medicines are a growing market to accommodate a growing worldwide demand. Herbal medicines have increased presence in functional foods, nutraceuticals, and natural health products [7]. The increased presence is a result of the numerous methods that herbal medicines can be processed and formulated. Herbal medicines can be processed and formulated as tablets, 
capsules, teas, tinctures, creams, oils, and liquids [7]. Although there is a rich history of use associated with herbal medicine, there are limitations. One of the major limitations to herbal medicine includes a lack of systematic approach to assess and demonstrate the efficacy, effectiveness, safety, and quality [8]. Herbal medicines are derived from plants, or their parts and the chemical composition can vary. The varying chemical composition is dependent upon the chemotype, the botanical species used, and the part of the plant used as well as extrinsic factors [9]. As a result of these factors and limitations, further research is necessary to establish the efficacy, quality, and safety of the products derived from medicinal plants. Unlike allopathic medicine which contain specific ingredients, a comprehensive characterization of compounds in herbal medicines is necessary [10].

\section{Medicinal Plants}

Throughout history, compounds of medicinal importance have been isolated from different parts of the plants. Secondary metabolites are a diverse group of compounds that are derived from primary metabolites. Unlike primary metabolites, the distribution of secondary metabolites is limited in the plant kingdom and can vary in both quantity and quality for any given plant species that is grown in different environments [11]. Medicinal plants are known to be rich in secondary metabolites. The classes of secondary metabolites with therapeutic value include phenolics, alkaloids, saponins, terpenes, lipids, glycosides, amines, insecticides, steroids, flavonoids, tannins, coumarins, chromones, xanthanes, stilbenes, lignans, and carbohydrates among other groups [12] These secondary metabolites are behind the medicinal properties of the plants including but not limited to antitumorigenic, antiinflammatory, antioxidant, antiseptic, antimicrobial. The biological effects of these secondary metabolites provide the scientific basis behind the use of herbal medicine and Ayurveda in modern medicine. It is important to note that the medicinal effect is due to more than one secondary metabolite. In recent years, secondary metabolites have gained commercial importance and the potential to alter the production of bioactive plant metabolites using tissue culture technology [11]. Secondary metabolites are unique to superior plants which are plants that possess flowers and consequently seeds; these plants are also known as spermatophytes [13]. Secondary metabolites tend to be most concentrated in female flowers of the plant.

\section{Female Flowers Versus Male Flowers}

Angiosperms, approximately 352,000 of known plant species, are flowering plants and the flowers are what allows plants to reproduce by making seeds [14]. Plants can be male, female, or hermaphrodites. A large number of flowering plants are hermaphrodites, exhibiting both male and female sexual characteristics [15]. Sexual dimorphism are the differences among male and female plants of a given dioecious flowering plant species [15]. It has been found that male and female plants differ in vegetative and reproductive traits [15]. There are structural differences in the makeup of male and female flowers. The male flower includes the stamens which consists of a stalk or filaments that supports the anther at the top, and the anther produces the pollen. The female flower contains organs called the stigma, ovary, and style which make up the pistil or carpel. At the top is the stigma that collects pollen, ovary at the bottom where fertilization occurs, and in between is the style that supports the stigma [16]. Other differences in male and female flowers include growth rate, mortality rate, reproductive effort, strength, and flowering time [15]. The cost of reproduction is generally more in females compared to males [15]. Some support that the differences between males and females are linked to the roles that they play in sexual reproduction [17]. For example, male inflorescence will not only develop earlier, but males will also flower earlier than females [17]. There are also differences in attraction to floral fragrance. For example, a study showed that a majority of the male species of a sample species population released more volatiles per flower [18]. This could however also be associated with larger flower size in males. However, female flowers are known to have more secondary metabolites than male flowers. In recent times, research has been geared more towards the study of secondary metabolites in various regions of the plant, especially the flower in medicinal plants such as cannabis, saffron, and Epiphyllum oxypetalum.

\section{Cannabis}

Cannabis belongs to the family Cannabaceae with three species, C sativa [19]. Of the three species, C. sativa has a rich history of use as a medicinal plant and serves many other purposes. Some of the other uses of C. sativa include it being used as a source of fiber, food, and oil [20]. As a medicinal plant, cannabis use dates back to thousands of years. The first account of the plant's medicinal use was during the 6th century B.C. from the Middle East and Asia and was then introduced to western medicine during the early 19th century [21]. C. sativa contains numerous secondary metabolites that have therapeutic value. The plant contains more than 540 compounds that are important for medicinal use [22]. These compounds include cannabinoids, terpenoids, flavonoids, and alkaloids that are mainly concentrated in the trichome cavity of the female flowers [20,23]. Cannabis, a well-researched crop, has numerous applications and has been used medicinally for numerous years. Cannabis is well studied, in that hundreds of secondary metabolites in cannabis have been identified to have therapeutic value with the concentration of cannabinoids the highest in terminal flowers [24]. The therapeutic value of Cannabis is largely dependent on phytocannabinoid production by the plant. 
Out of the cannabinoids present in Cannabis, tetrahydrocannabinol (THC) and cannabidiol (CBD) are the most studied and are the main biologically active cannabinoids [24-26]. Along with cannabinoids, the plant is also rich in terpenoids and flavonoids and other secondary metabolites with more than 540 phytochemicals identified including but not limited to CBD, THC, cannabigerol (CBG), cannabinol (CBN), and cannabichromene (CBC) [27]. CBD, a major metabolite of $C$. sativa, has been shown to have analgesic, anti-inflammatory, anxiolytic, anticonvulsant, and cytotoxic effects
[28]. THC, the psychoactive component, has been used as an anti-vomiting drug and as an appetite stimulant [29]. CBG, the least studied phytocannabinoid, has been suggested to have many applications such as an analgesic, anti-inflammatory, and neuroprotective agent [30]. CBN has shown the potential to have antibacterial activity [31]. CBC has shown to have anti-inflammatory and antinociceptive activity [32]. The common metabolites of Cannabis are shown in Figure 1.

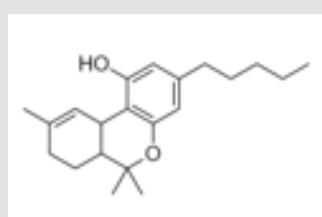

THC

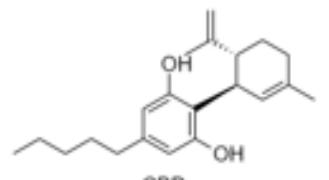

cep

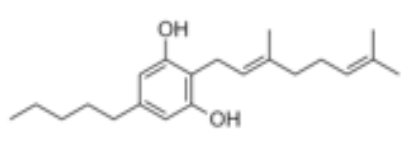

CBG

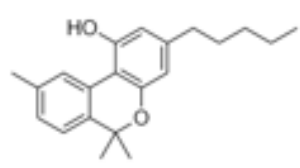

$\mathrm{CBN}$

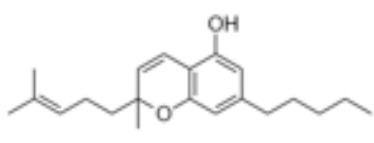

$\mathrm{CBC}$

Figure 1: Focal Group Discussion themes obtained from participant's records.

\section{Saffron}

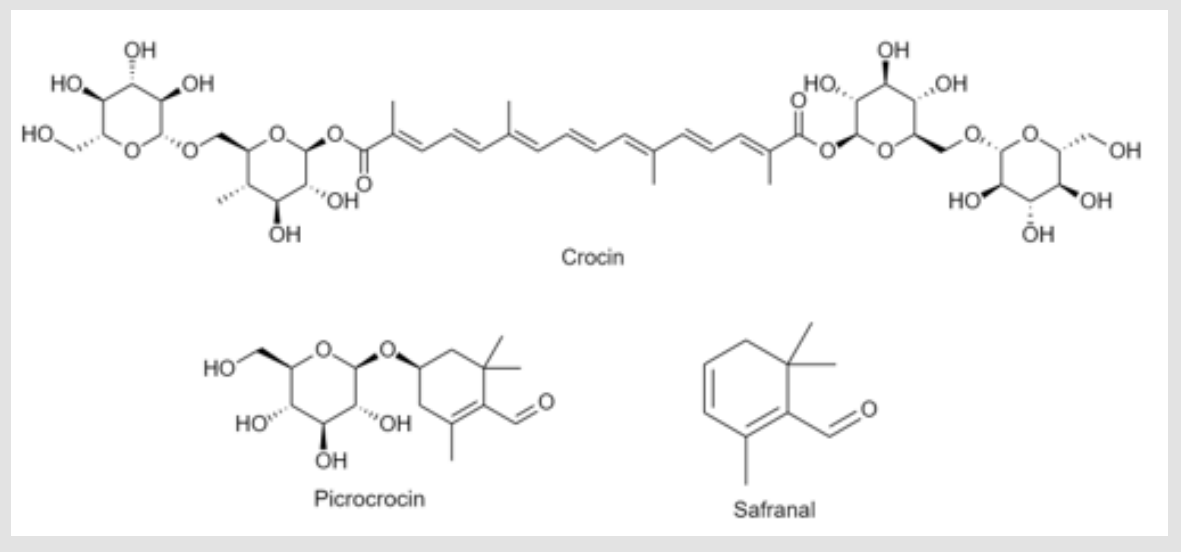

Figure 2: Biologically active compounds of Saffron.

Saffron, which are the dried stigmas of Crocus sativus, is a highly valued crop that is a member of the Iridaceae family [33]. One of the reasons saffron is considered expensive is because of the demand for intensive labor - farmers manually pick the flowers and isolate the stigmas [34-35]. It is an ancient spice, whose use dates back to thousands of years, and serves many purposes. Saffron has been used as a spice in cuisines, in cosmetics, and as a coloring agent in the textile industry [36]. Recently, saffron has gained renewed interest due to the potential health benefits. Saffron has been attributed with many therapeutic properties. Saffron has shown to have anodyne, antidepressant, antispasmodic, aphrodisiac, diaphoretic, expectorant, and emmenagogue effects [37]. In the same review by Alam, et al. [37], it was also mentioned that saffron extract has antinociceptive, anti-inflammatory, antitumor, anticonvulsant activities. These activities have been attributed to the compounds found in saffron. Chemical analysis has shown the presence of approximately 150 volatile and non-volatile compounds [38,39]. Of these 150 compounds, there are 3 biologically active compounds that are key. These compounds are crocin, picrocrocin and safranal, as shown in Figure 2, are responsible for the color, flavor, and aroma 
respectively $[38,40]$. Crocin, a vital saffron pigment and carotenoid, has been found to have antioxidant activity $[38,40]$. Crocin traps free radicals, highly reactive chemicals that have the potential to cause harm, and thereby protecting cells from oxidation $[40,41]$. Although picrocrocin has not shown to have medicinal properties, it is a precursor for safranal [40]. Safranal has been used for the treatment of cardiovascular and neurological disorders [40].

\section{Epiphyllum Oxypetalum}

Epiphyllum oxypetalum, often referred to as Brahma Kamalam or the Queen of the Night among other names, is a plant belonging to the Cactaceae family that is relatively less known as a medicinal plant and more known as an ornamental plant [42]. In fact, research is currently very limited on this crop. This plant has been used traditionally in Malay medicine, and it has been used to treat bloody phlegm and cough, uterine bleeding, and shortness of breath in the elderly. The plant is also believed to have the ability to neutralize blood clotting and limit pain $[43,44]$. In addition, the stem of the plant has been implicated in curing cardiac affections and dropsy, and the flowers are used in treating wound abscesses and allow for quick healing [44]. In Vietnamese medicine, petals of faded blooms are used to make soups that have tonic and aphrodisiac properties [44]. Very little is known about the phytochemicals in Brahma Kamalam due to the lack of published research on this plant. Dhandekhar et al. [2015]., reported phytochemical analysis on leaf extracts from Epiphyllum oxypetalum in which the compounds identified which were reported to possess anti-inflammatory, antioxidant, and antimicrobial activity. More recently, Jayashree, et al. [45] have reported the phytochemical analysis on the flower extracts of Brahma Kamalam.

Phytochemical analysis of Epiphyllum oxypetalum flower extracts detected the presence of alkaloids, saponin, protein, terpenoids, flavonoids, tannin, and steroids [45]. This same study by Jayashree, et al. [45] also performed a gas chromatography- mass spectrometry (GC-MS) analysis of the phytochemical compounds found in the flower extract of the Brahma Kamalam in which they detected 11 compounds as shown in Figure 3. The first compound they detected was hexadecanoic acid, ethyl ester, a palmitic fatty acid, which is known to be an antioxidant, flavor component, hypocholesterolemic, nematicide, pesticide, lubricant, antiandrogenic, hemolytic, a 5-alpha reductase inhibitor, and antipsychotic $[43,46]$. Nonadecanoic acid is another fatty acid which is known to have anticancer and antiproliferative activities [47]. Oleic acid is also a fatty acid which is an anticancer and emulsion agent; it also aids in maintaining a healthy lipid profile and cholesterol levels $[48,49]$. There has been no activity reported for 11-tridecen-1-ol; however, this compound has been reported in an antimalarial polyherbal formulation [50]. 1-octadecyne has been reported to have anti-inflammatory, cytotoxic, and antimicrobial activities [51]. Hexadecanal has the medicinal properties of playing a role in protein dimerization and neuropeptide [52]. It is also an antioxidant, hypocholesterolemic, antiandrogenic and hemolytic [45]. Spiro[androdt-5-ene-17,1-cyclobutan]-2-1-3hydroxy has antiarthritic, hepatoprotective, antiasthma, diuretic, and anti-inflammatory properties [46,53]. 1,6;3,4-dianhydro2-deoxy- $\beta$-D-Lyxo-hexopyranose exhibits antimicrobial activity [45,53]. Di-n-decylsulfone is known to have antifungal and antimicrobial properties [45,54]. 7-hydroxy-3[1,1-dimethyl prop2enyl] coumarin has antifungal, anticancer, and anti-inflammatory activity [45,55]. Pterin-6-carboxylic acid has been investigated for its inhibition of the phosphodiesterase 5 enzyme; it is also known to have antipsychotic, mood stabilizing, and anti-parasite activities as well. Epiphyllum oxypetalum has a lot of potential, but limited research is available on this plant. With more research on the phytochemicals of this plant and its potential uses and contributions to the medicinal activity of the plant, the diverse medicinal activity of this plant can be exploited for the betterment and for the future of modern medicine [56].

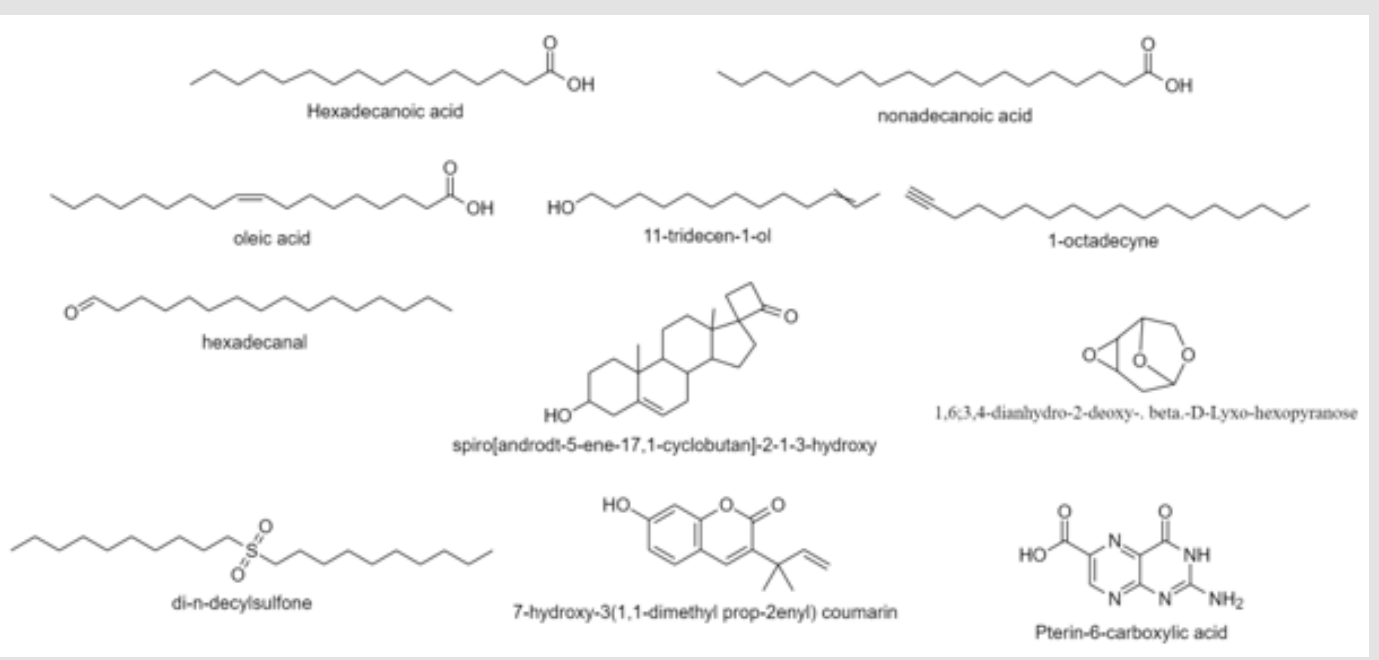

Figure 3: Compounds detected in Epiphyllum oxypetalum. 


\section{Conclusion}

Cannabis, saffron, and Epiphyllum oxypetalum are all medicinal plants on which various amounts of research has been conducted to study the plant and its secondary metabolites for its therapeutic value. These medicinal plants among others have the potential to advance modern medicine and aid in the treatment of many ailments plaguing the present and future of humanity.

\section{Acknowledgment}

The authors would like to acknowledge the School of Science, Engineering, and Technology at Penn State Harrisburg.

\section{Conflicts of Interest}

The authors declare no conflicts of interest regarding the publication of this review.

\section{References}

1. Farooqui AA, Farooqui T, Madan A, Ong JHJ, Ong, WY (2018) Ayurvedic medicine for the treatment of dementia: Mechanistic aspects. Evid Based Complement Alternat Med.

2. Kumar S, Dobos GJ, Rampp T (2017) The significance of Ayurvedic medicinal plants. J Evid Based Complementary Altern Med 22(3): 494501.

3. Bent $S$ (2008) Herbal medicine in the United States: review of efficacy, safety, and regulation. J Gen Intern Med 23(6): 854-859.

4. Kumar V, Kumar V (2009) An overview of herbal medicine. Int J Ph Sci 1(1): 1-20.

5. Kumar S, Parashar B (2019) A Review on Herbal Medicine: Past, Present and Future. IEARJ 3(6): 24-30

6. Wanjari AS, Wanjari DS (2019) An Overview on Herbal Medicine. Res J of Pharmacognosy and Phytochem 11(1): 14-17.

7. Sendker J, Sheridan H (2017) History and Current Status of Herbal Medicines. In Toxicology of Herbal Products. In: Pelkonen O, Duez P, Vuorela PM, Vuorela H (Eds.)., Toxicology of Herbal Products. (1), Springer, Cham, p. 11-27.

8. Ahmad AS, Sharma R (2020) Comparative Analysis of Herbal and Allopathic Treatment systems. Eur J Mol Clin Med 7(7): 2869-2876.

9. Bhosale VV, Banerjee D (2020) Scientific validation of herbal medicine. In: Sen S, Chakraborty R (Sen S, Chakraborty R), Herbal Medicine in India. (1), Springer, Singapore, pp. 573-579.

10. Feng W, Ao H, Peng C (2018) Gut microbiota, short-chain fatty acids, and herbal medicines. Front Pharmacol 9: 1354

11. Jain C, Khatana S, Vijayvergia R (2019) Bioactivity of secondary metabolites of various plants: a review. Int J Pharm Sci Res 10(2): 494498.

12. Hussein RA, El-Anssary AA (2019) Plants secondary metabolites: the key drivers of the pharmacological actions of medicinal plants. In: Builders PF (Eds.)., Herbal Medicine. IntechOpen, London, United Kingdom, p. 1133.

13. Mendoza N, Silva EME (2018) Introduction to phytochemicals: secondary metabolites from plants with active principles for pharmacological importance. In: Asao T, Assaduzzaman M (Eds.)., Phytochemicals: source of antioxidants and role in disease prevention. IntechOpen, London, United Kingdom, p. 25-47.
14. Paton AJ, Brummitt N, Govaerts R, Harman K, Hinchcliffe S, et al. (2008) Towards Target 1 of the Global Strategy for Plant Conservation: a working list of all known plant species - progress and prospects. TAXON 57(2): 602-611.

15. Barrett SC, Hough J (2013) Sexual dimorphism in flowering plants. J Exp Bot 64(1): 67-82

16. Amasino RM, Cheung AY, Dresselhaus T, Kuhlemeler C (2017) Focus on Flowering and Reproduction. Plant Physiol 173(1): 1-4.

17. Llyod DG, Webb CJ (1977) Secondary sex characters in plants. Bot Rev 43: 177-216.

18. Ashman TL (2009) Sniffing out patterns of sexual dimorphism in floral scent. Funct Ecol 23(5): 852-862.

19. Halawa OI, Furnish TJ, Wallace MS (2018) Role of cannabinoids in pain management. In: Benzon HT, Raja SN, Fishman SM, Liu SS, Cohen SP (Eds.)., Essentials of Pain Medicine. Elsevier, Philadelphia, Pennsylvania, United States of America, pp. 509-520.

20. Bonini SA, Premoli M, Tambaro S, Kumar A, Maccarinelli G, et al. (2018) Cannabis sativa: A comprehensive ethnopharmacological review of a medicinal plant with a long history. J Ethnopharmacol 227: 300-315.

21. ElSohly MA, Radwan MM, Gul W, Chandra S, Galal A (2017) Phytochemistry of Cannabis sativa L. Prog Chem Org Nat Prod 103: 1-36.

22. Lal S, Shekher A, Puneet, Narula AS, Abrahamse H, et al. (2020) Cannabis and its Constituents for Cancer: History, Biogenesis, Chemistry and Pharmacological Activities. Pharmacol Res 163: 105302.

23. Farag S, Kayser $O$ (2017) The cannabis plant: botanical aspects. In: Preedy VR (Edt.)., Handbook of Cannabis and Related Pathologies. Academic Press, London, United Kingdom, p. 3-12.

24. Bernstein N, Gorelick J, Koch S (2019) Interplay between chemistry and morphology in medical cannabis (Cannabis sativa L.). Ind Crop Prod 129: $185-194$

25. Flores-Sanchez IJ, Verpoorte R (2008) Secondary metabolism in cannabis. Phytochem Rev 7: 615-639.

26. Marcu JP (2016) An Overview of Major and Minor Phytocannabinoids. In: Preedy VR (Edt.)., Neuropathology of Drug Addictions and Substance Misuse. Academic Press, London, United Kingdom, pp. 672-678.

27. Andre CM, Hausman J-F, Guerriero G (2016) Cannabis sativa: The Plant of the Thousand and One Molecules. Front Plant Sci 7: 19.

28. Fitzcharles MA, Clauw DJ, Hauser W (2020) A cautious hope for cannabidiol (CBD) in rheumatology care. Arthritis Care Res.

29. Gonçalves J, Rosado T, Soares S, Simão AY, Caramelo D, et al. (2019) Cannabis and its secondary metabolites: Their use as therapeutic drugs, toxicological aspects, and analytical determination. Medicines (Basel) 6(1): 31

30. Deiana S (2017) Potential medical uses of cannabigerol: a brief overview. In: Preedy VR (Edt.)., Handbook of Cannabis and Related Pathologies. Academic Press, London, United Kingdom, pp. 958-967.

31. Fathordoobady F, Singh A, Kitts DD, Pratap Singh A (2019) Hemp (Cannabis Sativa L.) extract: Anti-Microbial properties, methods of extraction, and potential oral delivery. Food Rev Int 35(7): 664-684.

32. Schofs L, Sparo MD, Sánchez Bruni SF (2021) The antimicrobial effect behind Cannabis sativa. Pharmacol Res Perspect 9(2): e00761.

33. Shafiee M, Arekhi S, Omranzadeh A, Sahebkar A (2018) Saffron in the treatment of depression, anxiety, and other mental disorders: Current evidence and potential mechanisms of action. J Affect Disord 227: 330337.

34. Kahriz PP (2020) Saffron (Crocus sativus L.) Cultivation in Turkey. In: Sarwat M, Sumaiya S (Eds.)., Saffron. Elsevier, p. 33-43. 
35. Leone S, Recinella L, Chiavaroli A, Orlando G, Ferrante C, et al. (2018) Phytotherapic use of the Crocus sativus L. (Saffron) and its potential applications: A brief overview. Phytother Res 32(12): 2364-2375.

36. Guclu G, Kelebek H, Selli S (2020) Saffron (Crocus sativus L.): Its Aroma and Key Odorants. In: Sarwat M, Sumaiya S (Eds.)., Saffron. Elsevier, p. 69-82.

37. Farhan S, Shamsi S, Alam MT, Perveen A (2020) Saffron (Crocus sativus L.): A Review of its Ethnopharmacological value. Am J PharmTech Res $10(4)$.

38. Mzabri I, Addi M, Berrichi A (2019) Traditional and modern uses of saffron (Crocus sativus). Cosmetics 6(4): 63.

39. Siddiqui MJ, Saleh MS, Basharuddin SNB, Zamri SHB, Bin Mohd Najib MH, et al. (2018) Saffron (Crocus sativus L.): As an antidepressant. J Pharm Bioallied Sci 10(4): 173-180.

40. Kothari D, Thakur R, Kumar R (2021) Saffron (Crocus sativus L.): gold of the spices-a comprehensive review. Hortic Environ Biotechnol.

41. Qadri H, Iqbal AM (2017) Medicinal properties of saffron. LS Int J Life Sci 6(1): 39-46.

42. Nyffeler R, Eggli U (2010) Molecular phylogenetics and a revised suprageneric classification of the family Cactaceae. Schumannia 6: 109149.

43. Dandekar R, Fegade B, Arvind N (2015) Evaluation of anti inflammatory activity of alcohol and aqueous extract of Epiphyllum oxypetalum leaves. World J of Pharm and Pharma Sci 4: 851-858.

44. Mahmad A, Shaharun MS, Saad B, Dash GK (2020) Epiphyllum oxypetalum haw: A lesser known medicinal plant. Indo Am J Pharm $4(10): 3670-3672$.

45. Jayashree P, Shalini M, Meenambiga SS, Suganya V (2020) Phytochemical Screening and GC-MS Analysis of Epiphyllum oxypetalum flower extracts. RJPT 13(12): 5893-5897.

46. Sermakkani M, Thangapandian V (2012) GC-MS Analysis of Cassia italica Leaf Methanol Extract. Asian J Pharm Clin Res 5(2): 90-94.

\section{ISSN: 2574-1241}

DOI: $10.26717 /$ BJSTR.2021.36.005929

Sairam Rudrabhatla. Biomed J Sci \& Tech Res

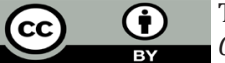

This work is licensed under Creative Commons Attribution 4.0 License

Submission Link: https://biomedres.us/submit-manuscript.php
47. Millaty INK, Wijayanti N, Hidayati L, Nuringtyas TR (2020) Identification of anticancer compounds in leaves extracts of agarwood (Aquilaria malaccensis (Lamk.)). IOP Conf Ser: Earth Environ Sci 457.

48. Jiang L, Wang W, He Q, Wu Y, Lu Z, et al. (2017) Oleic acid induces apoptosis and autophagy in the treatment of Tongue Squamous cell carcinomas. Sci Rep 7(1): 1-11.

49. Satpute SK, Banat IM, Dhakephalkar PK, Banpurkar AG, Chopade BA (2010) Biosurfactants, bioemulsifiers and exopolysaccharides from marine microorganisms. Biotechnol Adv 28(4): 436-450.

50. Iyamah P, Famuti A, Idu M (2017) GC-MS and Molecular Docking Studies for Identification of Anti-Malarial Compounds in Agbo-Iba PMII-a Polyherbal Formulation. Chemical Research Journal 2(1): 46-56.

51. Balabhaskar R, Vijayalakshmi K (2021) Identification of Secondary Metabolites from the Ethanol extract of the leaves of Bauhinia tomentosa by GC-MS Analysis. RJPT 14(5): 2735-2741.

52. Rao MR, Anisha G (2018) Preliminary phytochemical and GC MS study of one medicinal plant Carissa spinarum. Indo Am J Pharm Res 8: 414-421.

53. Ara I, Shinwari MMA, Rashed SA, Bakir MA (2013) Evaluation of antimicrobial properties of two different extracts of Juglans regia tree bark and search for their compounds using gas chromatography-mass spectrum. Int J Biol 5(2): 92.

54. Mahmud KN, Yahayu M, Sarip SHM, Rizan NH, Min CB, et al. (2016) Evaluation on efficiency of pyroligneous acid from palm kernel shell as antifungal and solid pineapple biomass as antibacterial and plant growth promoter. Sains Malays 45(10): 1423-1434.

55. Lacy A, O'Kennedy R (2004) Studies on coumarins and coumarin-related compounds to determine their therapeutic role in the treatment of cancer. Curr Pharm Des 10(30): 3797-3811.

56. Anitha J, Miruthula S (2014) Traditional medicinal uses, phytochemical profile and pharmacological activities of Luffa acutangula Linn. IJP 1(3): 174-183.

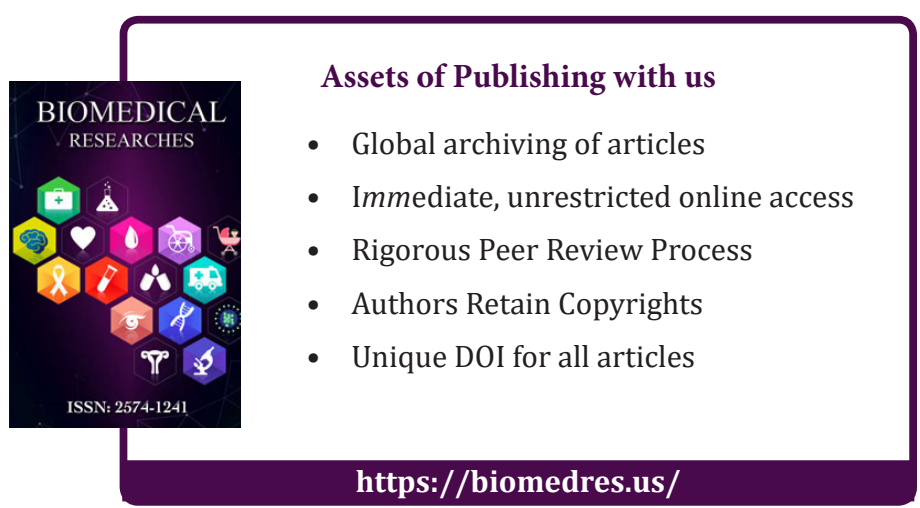

